\title{
Narrativas autobiográficas de mulheres com endometriose: que fenômenos permeiam os atrasos no diagnóstico?
}

\author{
I ${ }^{1}$ Aline Veras Morais Brilhante, ${ }^{2}$ Luiz Adriano Freitas Oliveira, \\ ${ }^{3}$ Lidia Andrade Lourinho, ${ }^{4}$ Almudena Garcia Manso I
}

Resumo: Este artigo objetiva compreender a rede de significados construídos intersubjetivamente que caracterizam o fenômeno da endometriose na vida das mulheres acometidas, equilibrando perspectivas micro e macrossociais. Trata-se de uma pesquisa qualitativa ancorada na técnica de narrativa autobiográfica do sociólogo Fritz Schütze, que explorou a experiência de 29 mulheres com endometriose. A análise foi realizada de acordo com o método reconstrutivo proposto por Schütze. Para além da estrutura esquemática baseada nos dados indexados, emergiam duas teorias: negligência estrutural legitimada por questóes de gênero e barreiras e atalhos na rede de assistência. As narrativas revelam a institucionalização de questôes de gênero nos serviços de saúde como reflexo de relaçóes embutidas na estrutura social. Negligência, psiquiatrização do sofrimento feminino, centralidade das ações na função reprodutiva e medicalização precoce do corpo feminino foram fenômenos sociais identificados nas narrativas. Esses aspectos estruturais, legitimados pela violência cultural, relacionam-se de forma simbiótica a lapsos na rede de assistência. O enfrentamento a esse fenômeno demanda mais do que a reorganização das linhas de cuidado segundo o paradigma da integralidade, embora esta emerja como uma possiblidade. É crucial a compreensão das microestruturas relacionadas ao gênero que fundamentam os arranjos sociais e a organização assistencial, produzindo violências institucionais e múltiplos sofrimentos.

> Palavras-chave: endometriose; diagnóstico tardio; narrativa; Sociologia; Saúde Coletiva.

\author{
${ }^{1}$ Universidade de Fortaleza \\ (UNIFOR). Fortaleza-CE, Brasil \\ (alineveras@unifor.br). ORCID: \\ 0000-0002-3925-4898 \\ ${ }^{2}$ Universidade de Fortaleza \\ (UNIFOR). Fortaleza-CE, Brasil \\ (adrianojs03@gmail.com). ORCID: \\ 0000-0002-8248-1404 \\ ${ }^{3}$ Saúde do Trabalhador, Faculdade \\ Ratio. Fortaleza-CE, Brasil \\ (lidiandrade67@gmail.com). \\ ORCID: 0000-0002-5883-9007 \\ ${ }^{4}$ Universidad Rey Juan Carlos. \\ Madrid, Espanha (almudena. \\ manso@urjc.es). ORCID: 0000 - \\ 0002-8781-5020
}

Recebido em: 16/05/2018 Aprovado em: 17/05/2019 Revisado em: 01/07/2019 


\section{Introdução}

A endometriose é uma doença crônica responsável por 30\% a 50\% dos casos de dor pélvica e infertilidade (PARAZZINI et al., 2017) e que afeta cerca de $11 \%$ das mulheres em idade reprodutiva (ZULLO et al., 2017). Apesar da prevalência e da existência de protocolos específicos (DUNSELMAN et al., 2014; JOHNSON et al., 2013; KENNEDY et al., 2005), a endometriose ainda é uma doença diagnosticada tardiamente (KLEIN et al., 2014). Deste modo, pesquisas que busquem compreender os fenômenos associados a esses atrasos apresentam grande relevância para a Saúde Pública.

A natureza crônica da endometriose, associada ao início tardio do tratamento, frequentemente contribui para a deterioração da qualidade de vida e desenvolvimento de sofrimento psíquico (WEINTRAUB et al., 2014). Além disso, a doença tem custos anuais estimados entre US\$ 11.688 e 12.941 por paciente (KOLTERMANN et al., 2017), sendo um terço destes valores referentes a custos diretos com a saúde e dois terços atribuídos à perda de produtividade (SIMOENS et al., 2012). Esses fatores impulsionaram a realização de estudos recentes a fim de elucidar as causas desses atrasos (BALLARD; LOWTON; WRIGHT, 2006; STAAL et al., 2016; WEINTRAUB et al., 2014). Dentre os principais fatores associados estão: falhas estruturais na rede (STAAL et al., 2016), baixa suspeição diagnóstica (BALLARD; LOWTON; WRIGHT, 2006), início dos sintomas na adolescência, uso indiscriminado de contraceptivos hormonais e realização frequente de diagnósticos alternativos (STAAL et al., 2016).

Essas informações, contudo, não conseguiram reduzir o problema, sendo o diagnóstico de endometriose frequentemente retardado em 8-10 anos (PARAZZINI et al., 2017). A baixa suspeição não se justifica pelo quadro clínico, uma vez que os sintomas cardinais da endometriose - dismenorreia, dispareunia e dor pélvica crônica não menstrual - são amplamente conhecidos (DUNSELMAN et al., 2014; KENNEDY et al., 2005). Paradoxalmente, enquanto mulheres com múltiplos sintomas têm maior probabilidade de ter endometriose (DUNSELMAN et al., 2014), a pluralidade de queixas associa-se frequentemente ao diagnóstico equivocado de causa funcional ou psicossomática (BALLARD; LOWTON; WRIGHT, 2006; NORHAYATI; SURIANTI; HAZLINA, 2015). Essas contradiçôes fortalecem a 
hipótese de que fatores socioculturais e subjetivos estejam amplamente envolvidos (NORHAYATI; SURIANTI; HAZLINA, 2015).

Partindo do pressuposto de que a explicação de fenômenos sociais demanda a compreensão da perspectiva dos indivíduos aliada à análise dos processos sociais (FERNANDES et al., 2017), emerge a pergunta: Como aspectos subjetivos e sociais se articulam na perpetuação do fenômeno do diagnóstico tardio da endometriose? Deste modo, esse artigo objetiva compreender a rede de significados construídos intersubjetivamente que caracterizam o fenômeno da endometriose na vida das mulheres acometidas, equilibrando perspectivas micro e macrossociais.

\section{Metodologia}

\section{Desenho do estudo}

Trata-se de uma pesquisa qualitativa ancorada na proposta metodológica da entrevista narrativa do sociólogo Fritz Schütze (SCHÜTZE, 1983). Este método baseia-se em múltiplas teorias, como a sociologia fenomenológica, o interacionismo simbólico e a etnometodologia, na busca por compreender as estruturas de processos pessoais e sociais de sofrimento e identificar recursos de enfrentamento (FERNANDES et al., 2017; MUYLAERT et al., 2014).

\section{Participantes do estudo}

O estudo explorou a experiência de 29 mulheres com endometriose acompanhadas no ambulatório de dor pélvica crônica de um hospital universitário em Fortaleza, Ceará, Brasil. A população elegível incluiu pacientes com mais de 18 anos de idade - com diagnóstico de endometriose confirmado por exame histopatológico que estavam sendo acompanhadas no ambulatório especializado. Foram excluídas mulheres com apenas uma consulta no ambulatório ou que ainda estavam em investigação diagnóstica. A média de idade de nossas informantes foi 32,72 anos. Nove (31\%) estavam solteiras, seis $(20,6 \%)$ divorciadas e 14 (48,2\%) casadas ou em união estável. Nove (31\%) informantes tinham filhos e oito (27,6\%) relatavam perdas gravídicas. Entre as entrevistadas havia mulheres residentes nas setes Secretarias Executivas Regionais (SER) que dividem a cidade, de modo que quatro residiam na SER-I, três na SER-II, quatro na SER-III, sete na SER-IV, cinco na SER-V, quatro na SER-VI e duas na SER do Centro. 


\section{Coleta de dados}

A coleta dos dados ocorreu entre outubro de 2016 e novembro de 2017, utilizando-se a técnica de Entrevista Narrativa Autobiográfica proposta por Schütze, que pode ser organizada em três etapas (SCHÜTZE, 1983). Na primeira delas, a informante produz um relato espontâneo, sem intervençôes do entrevistador, a partir de uma pergunta gerativa (JOVCHELOVITCH; BAUER, 2002). Nesta pesquisa, adotamos o questionamento: "Estou pesquisando histórias de vida de mulheres com endometriose e gostaria de conhecê-la melhor. Para isso, peço que você conte a sua história do modo que achar conveniente. Você pode levar o tempo que quiser, começar e terminar como desejar. Para que você fale livremente, eu não vou interrompê-la. Você deve me dizer quando a história acabou e somente depois eu farei algumas perguntas para esclarecer o que não entendi bem. Certo?”. Em seguida, foram realizadas "perguntas imanentes", visando ao esclarecimento de ambiguidades, passagens implausíveis ou não compreendidas. A terceira etapa congrega as "perguntas exmanentes", nas quais o gravador é desligado e o entrevistador faz perguntas que refletem o interesse do pesquisador e que geram respostas de argumentação, racionalização e teorização da parte do informante (JOVCHELOVITCH; BAUER, 2002; SCHÜTZE, 1983). As entrevistas duraram entre 35 e 150 minutos. Após cada entrevista, foi realizada a transcrição dos áudios e dos relatos posteriores à interrupção da gravação. Realizou-se a limpeza das marcas de oralidade, de modo a se construir narrativas que evidenciassem as experiências vividas. Após a estruturação das narrativas, estas foram reapresentadas para cada informante, de modo a obter a validação das informaçóes. Aproveitamos esse momento para obter dados percebidos como incompletos ou ausentes no momento da organização das narrativas. A análise inicial foi realizada de forma dinâmica, após cada coleta. A saturação foi considerada atingida quando não surgiram novas categorias a partir dos dados (SAUNDERS et al., 2017).

\section{Procedimentos de análise}

O método de análise e interpretação proposto por Schütze visa a reconstruir as interpretaçóes subjetivas elaboradas pelo(a) narrador(a) em um processo de interrelação com os cursos factuais (SCHÜTZE, 1983).

Após a transcrição detalhada das gravaçóes e o registro dos apontamentos, iniciamos a análise formal. Nessa etapa foram identificados os esquemas 
comunicativos (descrição, narração e argumentação), suas funçôes representacionais e comunicativas e os marcadores linguísticos e paralinguísticos (APPEL, 2005). Os dados foram então divididos em material indexado e não indexado. $\mathrm{O}$ primeiro corresponde ao conteúdo racional e concreto, que pode ser ordenado cronologicamente, permitindo a construção de trajetórias. $\mathrm{O}$ material não indexado expressa conteúdos subjetivos, como juízos de valor, sentimentos, reflexóes e sabedorias de vida, permitindo a análise do autoentendimento das entrevistadas (JOVCHELOVITCH; BAUER, 2002; SCHÜTZE, 1983). O conteúdo indexado foi descrito e estruturado, permitindo a análise detalhada e em sequência de cada segmento da narrativa. Na etapa seguinte, investigamos as dimensões não indexadas do texto, reunindo e analisando as atividades de autoteorização de modo individual e comparativo (MUYLAERT et al., 2014). As trajetórias individuais foram em seguida comparadas e codificadas de modo a extrair regularidades e contrastes (JOVCHELOVITCH; BAUER, 2002). A partir das etapas anteriores, nas quais categorias foram elaboradas e confrontadas sistematicamente, foi construído um modelo teórico sobre a trajetória biográfica das mulheres com endometriose.

\section{Procedimentos éticos}

O projeto desta pesquisa obteve aprovaçáo ética do Comitê de Ética da Universidade de Fortaleza com o número 52942116.8.0000.5052. Os dados serão apresentados preservando o anonimato das participantes, identificada pela letra "A" seguida de numeração. Após a identificação, segue entre parênteses o intervalo de tempo do início dos sintomas ao diagnóstico presuntivo em anos e o tempo seguinte até o acesso ao serviço especializado.

\section{Resultados}

A estruturação dos dados indexados permitiu a construção de uma trajetória esquemática individual, ordenando cronologicamente os atrasos relacionados ao diagnóstico e o acesso ao serviço especializado. Essas trajetórias foram analisadas comparativamente, permitindo a organização coletiva desses dados, como ilustra a figura 1 . $\mathrm{O}$ atraso mais significativo foi identificado entre o início dos sintomas e a suspeita diagnóstica (13,52 anos em média). 
Figura 1. Trajetória sistematizada das participantes do estudo

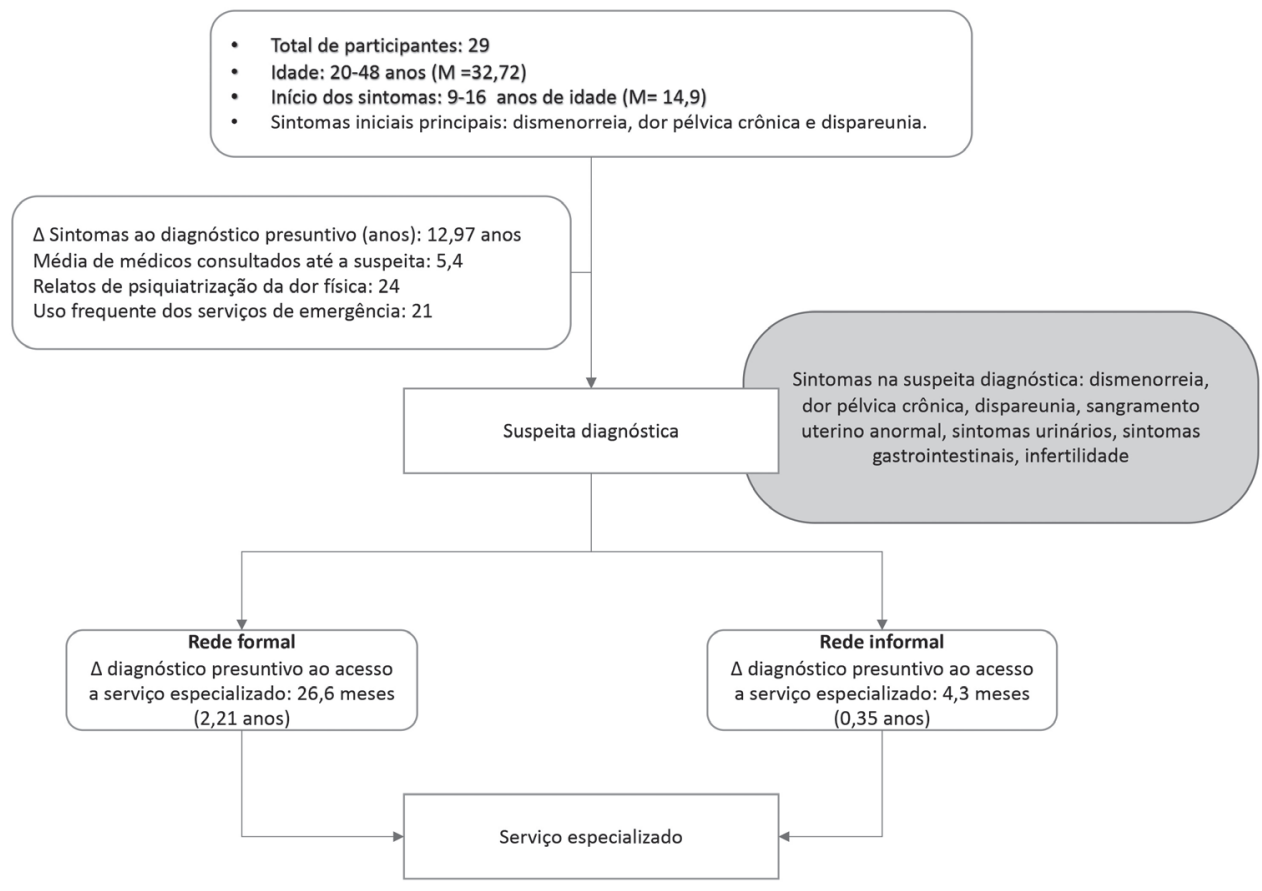

Para além da estrutura esquemática, emergiam das narrativas duas categorias que embasam o modelo teórico elaborado neste artigo: negligência estrutural legitimada por questóes de gênero e abismos e atalhos na rede de assistência.

\section{Negligência estrutural legitimada por questóes de gênero}

As narrativas revelam a institucionalização de questóes de gênero nos serviços de saúde como reflexo de relaçóes hierarquicamente embutidas na estrutura social. O curso clínico da endometriose nas narrativas materializou-se em sintomas que, apesar de conhecidos, foram sistematicamente desvalorizados pelos profissionais de saúde. A10 (17 anos; 24 meses) ilustra esse processo ao afirmar:

$\mathrm{Na}$ época da minha regra, eu não pisava no chão de tanta dor. [...] Fui pro ginecologista e ele disse que era normal.

Esses atrasos, contudo, não estão atrelados à imperícia dos profissionais. As narrativas demonstram que, para além conhecimento consolidado sobre o tema, o que há é negligência. A28 (5 anos; 36 meses) nos narra: 
[...] já tinha ido várias vezes pra ela [médica]. Aí um dia eu perguntei 'doutora, não é endometriose não o que eu tenho?' Eu tinha visto na televisão e era justinho o que eu sentia. Na hora ela olhou pra mim e disse: 'pode ser sim, porque você tem cólica muito forte e dói na relação, né?

Essa tese é corroborada por A27 (14 anos; 5 meses), que manifesta questionamento semelhante ao que motivou essa pesquisa:

Hoje que eu entendo melhor, eu não sei por que demorou tanto pra descobrirem. Tá até na televisão o tempo todo. Se você tem cólica forte, dor na hora do sexo e não consegue engravidar, vai atrás que é endometriose. Aí, me diz por que é que eu, com isso aí tudo, demoraram 14 anos pra saberem o que eu tinha?

A própria narradora, baseando-se no empirismo vivenciado na própria pele, nos fornece uma hipótese:

Ninguém valoriza a dor de mulher. Nem médico, nem marido, nem ninguém. Mulher sofre e a gente se acostuma com isso. É por isso que ninguém liga.

Como toda construção sociocultural, a negligência da dor da mulher não é exclusividade dos profissionais da saúde. Ela está institucionalizada, naturalizada e invisibilizada dentro das estruturas sociais. A16 (9 anos; 36 meses) narrou o descaso de sua família ao relatar:

Perdi as contas de quantas vezes ouvi "quando casar passa", "ave, que mulher mole",

"imagina quando for pra parir". Minha mãe passou a vida dizendo que eu era fraca pra dor.

Nesse contexto, a própria mulher pode introjetar essas premissas e deixar de buscar assistência. Foi o que aconteceu com A5 (20 anos; 1 mês):

Quando eu tinha relação eu sentia dor. Perguntei pro médico e ele disse que era normal. Eu acreditei, porque todo mundo diz que é normal. [...] Minha mãe, minhas irmãs, todo mundo dizia. [...] Só procurei de novo quando ficou insuportável.

Outra faceta do mesmo fenômeno amplamente naturalizada na sociedade foi a psiquiatrização da mulher com endometriose. Neste contexto, A27 (14 anos, 5 meses) evidencia as questóes de gênero e a violência embutidas nesse processo:

Minha irmã passou a vida com dor e tratando com fluoxetina. Minha mãe também tem uma ruma de dor e toma fluoxetina e diazepam. Já reparou que quando a mulher sente dor ou ela aguenta e não reclama ou é tratada que nem louca?

Embora não haja uma violência direta, naturaliza-se a imposição da aquiescência do sofrimento físico. Essa cominação tem base em processos produzidos por sistemas 
socioculturais e termina por gerar sofrimento psíquico, consequente e não a causa da dor inicial. Esse fenômeno foi observado e descrito por A20 (13 anos; 3 meses):

Eu sentia dor direto: antes de menstruar, quando menstruava, quando tinha relação sexual, quando ia evacuar. Mas todos os médicos que eu fui antes dessa última disseram que era coisa da minha cabeça. [...] Meu namorado dizia que eu sou ansiosa, todo mundo dizia. Mas eu sou mesmo ansiosa. A diferença é que não foi a ansiedade que me deixou com dor. Foi a dor que me deixou ansiosa.

Outra marca das questôes socioculturais de gênero institucionalizada na assistência é o foco na função reprodutiva feminina. Em 19 das 29 narrativas, a suspeita de endometriose apenas emergiu com a comprovação da infertilidade, apesar das amplas queixas álgicas precedentes. A22 (15 anos; 36 meses) expóe esse fenômeno ao relatar que:

Toda vez era a mesma coisa. Eu ia no médico e ele dizia que era normal, que toda mulher tem cólica. Aí comecei ter dor na relação sexual e os médicos continuaram dizendo que era normal, que toda mulher tem dor em algumas posiçóes. Depois eu já tinha 35 anos e não engravidava. Foi só aí que suspeitaram que tinha algo errado.

Para além da inequívoca relevância da assistência à saúde reprodutiva da mulher, as narrativas evidenciam a redução da subjetividade feminina e de sua função sexual à sua capacidade reprodutiva, como percebeu A25 (15 anos; 36 meses):

Meu casamento tava por um fio. Porque eu não conseguia ter relaçấo sem dor. Ouvi de tudo. Que eu não amava meu marido. Que era ressecamento. Que eu fosse no psicólogo. Usei tanto creme vaginal! Aí decidi engravidar, porque disseram que quando tivesse menino passava tudo. Não consegui. Foi quando me mandaram pra cá pra investigar o problema.

A dispareunia foi relatada por 21 das 29 informantes. Destas, 14 relataram que essa queixa foi sistematicamente ignorada. Este fenômeno associa-se à construção sociocultural que silencia sobre a sexualidade feminina e a reduz ao seu papel de complementaridade da masculina. Neste sentido, A18 (15 anos; 24 meses) reproduz um discurso amplamente difundido culturalmente:

A gente faz sexo porque tem que fazer. Porque é importante pra relação. Homem não aguenta sem; então, mesmo com dor a gente faz. [...] Eu nunca tive [orgasmo], não sei como é, mas a mulher tem obrigação com o casamento. [...] Como ninguém sabia o que era a minha dor, eu achava que era porque eu era fria.

A medicalização precoce do corpo feminino também surgiu como fator associado ao diagnóstico tardio. Das 29 informantes, 15 fizeram uso de contraceptivos hormonais prescritos por profissionais de saúde para regularização do ciclo 
menstrual entre os 14 e os 17 anos de idade. Essa prática pode mascarar os sintomas e contribuir para o atraso no diagnóstico. A2 (18 anos; 2 meses), por exemplo, iniciou a medicação aos 15 anos:

[...] para regular a menstruação. Aí quando eu parava, vinha a cólica e o doutor mandava eu voltar. Eu náo queria usar. Me dava dor de cabeça e eu engordei, mas se eu parava a dor voltava. Um médico disse uma vez que eu tinha que escolher viver com dor ou engordar, mas nesse tempo ninguém nunca me falou que podia ser endometriose.

Esses aspectos estruturais — sustentados e legitimados por uma violência cultural — relacionam-se de forma simbiótica aos lapsos na rede de assistência

\section{Abismos e atalhos na rede de assistência}

O sofrimento inconcluso e sem causa determinada culmina na busca por diferentes profissionais. A média entre as nossas informantes foi de 5,3 médicos até a suspeita. Neste sentido, A11 (10 anos; 3 meses) relata:

Passei por nove, lembro a cara de todos. Mas se fosse um só, tinha dado na mesma, porque era sempre a mesma coisa. Nem examinam a gente, só pedem ultrassom.

A organização dos serviços em Redes de Atenção à Saúde (RAS) hierarquizadas com foco na APS deveria assegurar uma aproximação entre profissionais e comunidade, fomentando a promoção da saúde e a redução de exames desnecessários. As narrativas, contudo, demonstram o uso dos exames complementares para legitimar a ocultaçáo da dor da mulher, como continua a nos narrar A11 (10 anos; 3 meses):

Eu mostrei pro médico a ruma de transvaginal que eu já tinha. Todas normais. A última tinha 4 meses só. Mesmo assim, ele pediu outro. E depois disse que se desse normal de novo, era porque era coisa da minha cabeça.

A cronicidade dos sintomas e a pouca resolutividade da APS conduziram as mulheres na busca de atalhos que, em última análise, prejudicam ainda mais o fluxo na rede. Neste processo, todas as informantes buscaram a emergência em algum momento, 15 delas com periodicidade regular de 6 a 12 vezes ao ano. A8 (15 anos; 6 meses) é uma dessas mulheres:

Todos os meses era muita dor e eu acabava indo pro hospital. [...] Eu não sabia o que eu tinha, então era o único caminho.

A busca frequente por serviços de emergência favoreceu a cronificação do processo, contribuindo para o atraso no diagnóstico, como nos narra A7 (22 anos; 36 meses): 
Eu admito: parei de ir no posto. Desisti e fiquei indo na emergência todo mês. Passei anos nisso. A doutora falou que, como demorou muito a tratar, é por isso que meu caso ficou grave.

Nessa longa busca pelo controle do sofrimento, a presunção do diagnóstico não bastou para concluir a peregrinação. Embora a maioria (21 informantes) tenha recebido encaminhamentos para serviços de referência, apenas 13 acessaram o serviço especializado pelas vias formais, com uma demora de 2,19 anos entre o encaminhamento e a consulta. Destas, oito mulheres foram encaminhadas para outro ambulatório especializado (sete para o serviço de infertilidade e uma para a uroginecologia). A lentidão dos aparelhos que compóem as RAS, fenômeno uníssono nas narrativas, é exemplificada por A17 (10 anos; 24 meses):

Uma médica me deu um encaminhamento pro ambulatório de dor crônica. Com sete meses, vi que o encaminhamento perdeu a validade e eu tive que renovar. Renovei quatro vezes. Foram dois anos esperando com dor. Eu ia no posto e o médico só dizia que já tinha me encaminhado e que não tinha mais o que fazer e passava ibuprofeno.

A demora e a necessidade de uma resposta conduziram dez pacientes à busca pelas vias informais de acesso ao serviço. Uma dessas informantes foi A5 (20 anos; 1 mês):

Passei foi 20 anos com dor! Queria passar mais 20 esperando, não. Aí pedi pra minha cunhada que trabalha lá. Ela disse que ia tentar, porque não era fácil, mas mesmo assim conseguiu ligeiro.

Essa estrutura paralela fragiliza a rede, prejudicando as pessoas que aguardam o acesso formal, como percebe A7 (22 anos; 36 meses):

Eu tenho raiva porque eu passei três anos esperando. Depois que eu cheguei aqui, foi ótimo. Mas foram três anos e tem gente que consegue com meses só porque conhece alguém. [...] e é claro que se alguém entra na frente, é que nem furar fila. Tem alguém esperando certinho que não chega.

Os lapsos na rede explicam a demora no acesso ao especialista; contudo, não justificam a ausência de tratamento inicial para o controle dos sintomas álgicos. Em sendo levantada a suspeita diagnóstica, o profissional da APS pode iniciar um tratamento clínico preliminar. Essa experiência facilitou o percurso de A4 (4 anos; 18 meses) na busca por tratamento:

Eu fiquei um ano e meio esperando a consulta com a especialista. [...] mas foi a doutora do posto que começou o tratamento. Ela conversou comigo, me disse que podia ser endometriose por causa das coisas que eu sentia, que era muito parecido. Quando cheguei na especialista, ela fez o mapeamento, mas continuou o remédio, porque eu estava sem dor. [...] só precisou de cirurgia agora. 
Deste modo, fecha-se o ciclo com o retorno ao atraso na suspeição diagnóstica e à negligência em relação ao sofrimento feminino associada a esse fenômeno.

\section{Discussão}

As duas teorias extraídas das narrativas encontram-se em um ponto em comum: "a esfera simbólica da nossa existência [...] utilizada para justificar ou legitimar a violência direta ou estrutural” (GALTUNG, 1990, p. 291). Ou seja, a violência cultural legitima a violência estrutural — oculta em meio ao processo assistencial — e violências diretas materializadas principalmente na negligência evidenciada (GALTUNG, 1969; 1990). Os resultados descortinam discursos - tanto do senso comum como da ciência empírica - permeados por questôes de gênero. Estes camuflam as reais necessidades das mulheres e fomentam a psiquiatrização do seu sofrimento.

Sem encontrar respaldo na falta de um quadro clínico característico (DUNSELMAN et al., 2014; JOHNSTON; REID; HUNTER, 2015; KENNEDY et al., 2005; PARAZZINI et al., 2017; SOLIMAN; FULDEORE; SNABES, 2017), os atrasos no diagnóstico da endometriose relacionam-se à naturalização dos sintomas pela sociedade em geral, incluindo os profissionais de saúde (BALLARD; LOWTON; WRIGHT, 2006). Ocorre que a ciência — em sua suposta neutralidade — não é inerte às práticas historicamente contingentes que atuam no contínuo processo de formação das performatividades de gênero (BUTLER, 2006; 2011). Nesse sentido, o discurso biomédico hegemônico tem sido historicamente utilizado para mascarar como ontológicas dicotomias socialmente construídas (BRILHANTE; NATIONS; CATRIB, 2018). No caso específico das queixas álgicas, a crença culturalmente disseminada de que a mulher suporta melhor a dor do que o homem (BUDÓ et al., 2007) soma-se ao modo como as relaçôes de poder organizam-se em instituiçôes cunhadas na lógica patriarcal (ZANELLO, 2014; ZANELLO; COSTA e SILVA, 2012). Deste modo, observamos que os profissionais de saúde reproduzem essa falácia em suas práticas profissionais, culminando na negligência evidenciada nos resultados. Ressalte-se que a cultura não interfere apenas no modo como o outro percebe a nossa dor, mas também na nossa própria vivência da sensação dolorosa (BUDÓ et al., 2007). A mulher é educada de modo a estabelecer com a dor uma proximidade identitária. As dores do parto e as cólicas menstruais estão culturalmente táo arraigadas ao ideário de feminilidade, que não as suportar pode 
produzir uma ferida narcísica, o que culmina no seu silenciamento (COELHO et al., 2009; TOYE; SEERS; BARKER, 2014; ZANELLO, 2014).

Outra categoria que emergiu das narrativas foi a psiquiatrização da mulher com endometriose. A análise do campo da saúde mental sob o viés de gênero ainda é incipiente (ZANELLO; FIUZA; COSTA, 2015) e o discurso biomédico hegemônico ainda está ancorado na primazia das diferenças biológicas entre os sexos. A 5 a edição do Manual Diagnóstico e Estatístico de Transtornos Mentais (DSM), embora já mencione as questôes de gênero, ainda justifica diferenças na saúde mental de homens e mulheres como associadas principalmente a fatores orgânicos e "eventos do ciclo reprodutivo ao longo da vida" (AMERICAN PSYCHIATRIC ASSOCIATION, 2014, p. 15). Além disso, ao trazer que "mulheres têm mais chances de confirmar um transtorno depressivo, bipolar ou de ansiedade e de fornecer uma lista de sintomas mais abrangente do que homens" (p. 15) sem problematizar esse dado estatístico, o DSM-V ignora os fenômenos socioculturais que permeiam a feminilidade em suas dimensões materiais e simbólicas (COELHO et al., 2009; SIMÓES-BARBOSA et al., 2017). O sofrimento e o funcionamento narcísico dos sujeitos são atravessados por valores de gênero, de modo que a "quebra psíquica" mais frequente em mulheres não é um evento não aleatório (ZANELLO; FIUZA; COSTA, 2015). Deste modo, silenciar sobre o papel das vivências sociais de gênero na experiência do sofrimento psíquico reforça inadvertidamente o estigma social que associa a mulher à histeria, contribuindo para psiquiatrização de suas dores físicas (ZANELLO; COSTA E SILVA, 2012).

Em nossa sociedade binária, a assimilação dos papéis sociais de gênero depende de se obrigar o corpo a conformar-se com uma ideia histórica (BUTLER, 2006). Essa crença está tão imbricada na argamassa de nossa estrutura social, que as contradiçôes entre discurso e prática passam despercebidas. Por exemplo, embora a autonomia seja um dos pilares do II Plano Nacional de Políticas para as Mulheres (BRASIL, 2008), nossos resultados evidenciam que o controle dos corpos femininos segue normatizado nas práticas clínicas cotidianas. A prescrição indiscriminada de contraceptivos orais deslocados de sua função original (BALLARD; LOWTON; WRIGHT, 2006; STAAL et al., 2016) prejudicam duplamente a mulher com endometriose. Por um lado, a ação hormonal mascara os sintomas e retarda o diagnóstico. Por outro, o micropoder relacionado ao controle dos corpos femininos (FOUCAULT, 1988) contribuem para a perpetuação do ideário de gênero que normatiza a negligência 
evidenciada nos resultados. Vale aqui esclarecer que contraceptivos hormonais podem ser utilizados no tratamento sintomático da endometriose, desde que em uso contínuo (KENNEDY et al., 2005; DUNSELMAN et al., 2014). Além disso, seu uso não impede ou retarda o avanço da doença, de modo que demanda monitoramento (PARAZZINI et al., 2017; JOHNSON et al., 2013; KLEIN et al., 2014, KOLTERMANN et al., 2017). Deste modo, as narrativas expóem que dispositivos históricos (FOUCAULT, 1988) encontram suporte em uma cientificidade engendrada (ZANELLO; FIUZA; COSTA, 2015), que mercantiliza a patologização da fisiologia feminina (CARVALHO; DIMENSTEIN, 2004; MIGUELOTE; CAMARGO JR, 2010) enquanto ocultam como fisiológicos ou psiquiátricos os sofrimentos orgânicos.

Os mecanismos que culminam na imposição do sofrimento e de sua aceitação pelas mulheres, embora não possuam intenção violenta, atuam como tal. A violência aqui emerge como consequência de um processo que está embutido "na estrutura e aparece como desigualdade de poder". (GALTUNG, 1969, p. 171). Deste modo, os lapsos assistenciais observados estão em grande parte relacionados a um discurso social que legitima uma violência de gênero, que é estrutural em nossa sociedade (ZANELLO; COSTA E SILVA, 2012).

Ainda que as mulheres sejam alvo frequente de atenção pelas políticas públicas de saúde, há uma tendência de se reduzir essas açóes à prevenção de cânceres ginecológicos e aos aspectos reprodutivos — seja assistência à saúde materno-infantil, seja o planejamento familiar, reduzido ao controle de natalidade (TOYE; SEERS; BARKER, 2014). Nossas informantes nos narram que a infertilidade culmina em diagnósticos mais rápidos, reproduzindo nas próprias vivências o que fora comprovado em outros estudos (SOLIMAN; FULDEORE; SNABES, 2017; STAAL et al., 2016). Vale aqui reafirmar a relevância do enfrentamento a doenças letais e da assistência à saúde maternoinfantil no âmbito da Saúde Pública. Contudo, é necessário enfatizar que a organização das RAS em linhas de cuidado orientadas por doenças ou ciclos de vida culmina em uma assistência fragmentada. Evidente que propostas de linhas de cuidado específicas não tolhem o profissional ou o impedem de assistir a pessoa de forma integral. Todavia, a organização da assistência em protocolos meramente técnicos e avaliados por indicadores numéricos torna-os impermeáveis à análise crítica das microestruturas. Cria-se assim um terreno fértil para a consolidação do biopoder (FOUCAULT, 1988) nas práticas assistenciais. Deste modo, é crucial 
destacar que, ao focarem a assistência à mulher em aspectos reprodutivos, os órgãos governamentais atuam como organizaçôes sociais legitimadoras dos discursos sobre os quais se estruturam os papéis de gênero (SCOTT, 1986).

A assistência sob o eixo da integralidade do cuidado demanda a compreensão das dimensões micropolíticas e relacionais do trabalho em saúde (CECILIO; MERHY, 2003; MALTA; MERHY, 2010). Essa perspectiva dispensa o debate sobre as questôes de gênero que permeiam os serviços de saúde. Neste sentido, a proposição da Linha do Cuidado Integral em Saúde (DUBOW et al., 2014; MALTA; MERHY, 2010) emerge como uma possiblidade, ao propor "a permeabilidade do técnico ao não técnico e a afluência de diferentes interesses e projetos, intersubjetivamente tratados entre os sujeitos" (SILVA; SANCHO; FIGUEIREDO, 2016, p. 845). A legitimação das questóes de gênero, contudo, está tão arraigada na estrutura social que corrompe frequentemente as próprias estratégias de enfrentamento (ROMAGNOLI, 2015). Deste modo, é urgente descortinar essas questóes e suas relaçóes com as práticas assistenciais, de modo a contribuir para a estruturação de linhas de cuidado mais justas e efetivas para a assistência das mulheres com endometriose.

\section{Conclusão}

As narrativas de nossas informantes expóem a colonização do corpo e das vidas femininas por questóes de gênero como uma violência estrutural. Estes elementos reforçam fragilidades na RAS e contribuem para o diagnóstico tardio da endometriose. $\mathrm{O}$ enfrentamento a esse fenômeno demanda mais do que a reorganização das linhas de cuidado segundo o paradigma da integralidade, embora esta emerja como uma possiblidade. É crucial a compreensão das microestruturas relacionadas ao gênero que fundamentam os arranjos sociais e a organização assistencial, produzindo violências institucionais e múltiplos sofrimentos. ${ }^{1}$

\section{Referências}

AMERICAN PSYCHIATRIC ASSOCIATION. Manual diagnóstico e estatístico de transtornos mentais: DSM-5. 5. ed. Porto Alegre: Artmed, 2014.

APPEL, M. The autobiographic-narrative interview: the theoretical implications and the analysis procedure of a case study about cultural changes among the Otomi Indians in Mexico. Forum: Qualitative Social Research, v. 6, n. 2, p. 1-35, 31 maio 2005. 
BALLARD, K.; LOWTON, K.; WRIGHT, J. What's the delay? A qualitative study of women's experiences of reaching a diagnosis of endometriosis. Fertility and Sterility, v. 86, n. 5, p. $1296-$ 1301, nov. 2006.

BRASIL. Presidência da República. Secretaria Especial de Políticas para as Mulheres. II Plano Nacional de Políticas para as Mulheres. Brasília: Secretaria Especial de Políticas para as Mulheres, 2008. Disponível em: <http://portal.mec.gov.br/dmdocuments/planonacional_ politicamulheres.pdf>. Acesso em: 6 abr. 2018.

BRILHANTE, A. V. M.; NATIONS, M. K.; CATRIB, A. M. F. 'Give her booze and she'll loosen up': Gender violence in northeast Brazilian forró lyrics and parties. Cadernos de Saúde Pública, v. 34, n. 3, 2018.

BUDÓ, M. de L. D. et al. A cultura permeando os sentimentos e as reaçóes frente à dor. Revista da Escola de Enfermagem da USP, v. 41, n. 1, p. 36-43, mar. 2007.

BUTLER, J. Gender trouble: feminism and the subversion of identity. Londres: Routledge, 2006. Bodies that matter: on the discursive limits of sex. Londres: Routledge, 2011.

CARVALHO, L. de F.; DIMENSTEIN, M. O modelo de atenção à saúde e o uso de ansiolíticos entre mulheres. Estudos de Psicologia. Natal, v. 9, n. 1, p. 121-129, abr. 2004.

CECILIO, L. C. de O.; MERHY, E. E. A integralidade do cuidado como eixo da gestão hospitalar. In: PINHEIRO, R.; MATTOS, R. A. de (Orgs.). Construção da integralidade: cotidiano, saberes e práticas em saúde. Rio de Janeiro: IMS-Abrasco, 2003. p. 197-210.

COELHO, E. de A. C. et al. Integralidade do cuidado à saúde da mulher: limites da prática profissional. Escola Anna Nery Revista de Enfermagem, v. 13, n. 1, p. 154-160, 2009.

DUBOW, C. et al. Linha de cuidado como dispositivo para a integralidade da atenção a usuários acometidos por agravos neoplásicos de cabeça e pescoço. Saúde Debate, v. 38, n. 100, p. 94-103, 2014.

DUNSELMAN, G. A. J. et al. ESHRE guideline: management of women with endometriosis. Human Reproduction, v. 29, n. 3, p. 400-412, 1 mar. 2014.

FERNANDES, G. C. M. et al. Fritz Schütze's autobiographical narrative analysis applied to nursing research. Texto \& Contexto - Enfermagem, v. 26, n. 2, p. e04260015, 2017.

FOUCAULT M. História da sexualidade I: a vontade de saber. Rio de Janeiro: [s.n.], 1988.

GALTUNG, J. Violence, peace, and peace research. Journal of Peace Research, v. 6, p. 167-191, 1969. . Cultural violence. Journal of Peace Research, v. 27, n. 3, p. 291-305, 1 ago. 1990.

JOHNSON, N. P. N. P. et al. Consensus on current management of endometriosis. Human Reproduction, v. 28, n. 6, p. 1552-1568, 1 jun. 2013. 
JOHNSTON, J. L.; REID, H.; HUNTER, D. Diagnosing endometriosis in primary care: clinical update. The British journal of general practice, v. 65, n. 631, p. 101-2, 1 fev. 2015.

JOVCHELOVITCH, S.; BAUER, M. W. Entrevista narrativa. In: BAUER, M.; GASKELL, G. (Eds.). Pesquisa qualitativa com texto, imagem e som: um manual prático. Petrópolis: Vozes, 2002. p. 90-113.

KENNEDY, S. et al. ESHRE guideline for the diagnosis and treatment of endometriosis. Human Reproduction, v. 20, n. 10, p. 2698-2704, 1 out. 2005.

KLEIN, S. et al. What is the societal burden of endometriosis-associated symptoms? A prospective Belgian study. Reproductive BioMedicine, v. 28, n. 1, p. 116-124, jan. 2014.

KOLTERMANN, K. C. et al. Economic burden of endometriosis: a systematic review. Annals of Reproductive Medicine and Treatment, v. 2, n. 2, p. 1.115, 2017.

MALTA, D. C.; MERHY, E. E. O percurso da linha do cuidado sob a perspectiva das doenças crônicas não transmissíveis. Interface - Comunicação, Saúde, Educação, v. 14, n. 34, p. 593-606, 17 set. 2010.

MigUELOTE, V. R. da S.; CAMARGO JR, K. R. de. Indústria do conhecimento: uma poderosa engrenagem. Revista de Saúde Pública, v. 44, n. 1, p. 190-196, fev. 2010.

MUYLAERT, C. J. et al. Entrevistas narrativas: um importante recurso em pesquisa qualitativa. Rev Esc Enferm USP, v. 48, n. esp2, p. 193-199, 2014.

NORHAYATI, M. N.; SURIANTI, S.; HAZLINA, N. H. N. Metasynthesis: experiences of women with severe maternal morbidity and their perception of the quality of health care. Plos One, v. 10, n. 7, e0130452, 2015.

PARAZZINI, F. et al. Epidemiology of endometriosis and its comorbidities. European Journal of Obstetrics \& Gynecology and Reproductive Biology, v. 209, p. 3-7, fev. 2017.

ROMAGNOLI, R. C. Várias Marias: efeitos da Lei Maria da Penha nas delegacias. Fractal: Revista de Psicologia, v. 27, n. 2, p. 114-122, ago. 2015.

SAUNDERS, B. et al. Saturation in qualitative research: exploring its conceptualization and operationalization. Quality \& Quantity, p. 1-15, 14 set. 2017.

SCHÜTZE, F. Biographieforschung und narratives Interview. Neue Praxis, v. 13, n. 3, p. 283293, 1983.

SCOTT, J. W. Gender: a useful category of historical analysis. The American Historical Review, v. 91, n. 5, p. 1053-1075, dez. 1986.

SILVA, N. E. K. E; SANCHO, L. G.; FIGUEIREDO, W. dos S. Entre fluxos e projetos terapêuticos: revisitando as noçóes de linha do cuidado em saúde e itinerários terapêuticos. Ciência \& Saúde Coletiva, v. 21, n. 3, p. 843-852, mar. 2016. 
SIMOENS, S. et al. The burden of endometriosis: costs and quality of life of women with endometriosis and treated in referral centres. Human Reproduction, v. 27, n. 5, p. 1292-1299, 1 maio 2012.

SIMÓES-BARBOSA, R. H. et al. Abuso de drogas e transtornos alimentares entre mulheres: sintomas de um mal-estar de gênero? Cadernos de Saúde Pública, v. 33, n. 1, p. e00120816, 2017. SOliMAN, A. M.; FULDEORE, M.; SNABES, M. C. Factors Associated with time to endometriosis diagnosis in the United States. Journal of Women's Health, v. 26, n. 7, p. 788-797, 1 jul. 2017.

STAAL, A. H. J. H. J.; ZANDEN, M. van der; NAP, A. W. W. Diagnostic delay of endometriosis in the Netherlands. Gynecologic and Obstetric Investigation, v. 81, n. 4, p. 321-324, 2016.

TOYE, F.; SEERS, K.; BARKER, K. A meta-ethnography of patients' experiences of chronic pelvic pain: struggling to construct chronic pelvic pain as "real". Journal of Advanced Nursing, v. 70, n. 12, p. 2713-2727, dez. 2014.

WEINTRAUB, A. et al. Think endometriosis: delay in diagnosis or delay in referral to adequate treatment? Journal of Fertilization, v. 2, n. 3, p. 2-7, 6 jul. 2014.

ZANELLO, V. Saúde mental, mulheres e conjugalidade. In: STEVENS, C.; OLIVEIRA, S.; ZANELLO, V. (Eds.). Estudos feministas e de gênero: articulações e perspectivas. Florianópolis: Ed. Mulheres, 2014. p. 108-18.

ZANELLO, V.; COSTA E SILVA, R. M. Saúde mental, gênero e violência estrutural. Revista Bioética, v. 20, n. 2, p. 267-279, 5 set. 2012.

ZANELLO, V.; FIUZA, G.; COSTA, H. S. Saúde mental e gênero: facetas engendradas do sofrimento psíquico. Fractal: Revista de Psicologia, v. 27, n. 3, p. 238-246, 2015.

ZULLO, F. et al. Endometriosis and obstetrics complications: a systematic review and metaanalysis. Fertility and Sterility, v. 108, n. 4, p. 667-672.e5, out. 2017.

\section{Nota}

${ }^{1}$ A. V. M. Brilhante, L. A. Lourinho e A. G. Manso trabalharam na concepção, no planejamento da coleta, análise e interpretação dos dados, na revisão crítica relevante do conteúdo intelectual e aprovação final da versão a ser publicada. L. A. F. Oliveira trabalhou na concepção, coleta, análise e interpretação dos dados, na revisão crítica relevante do conteúdo intelectual e aprovação final da versão a ser publicada. 


\section{Abstract}

Autobiographic narratives of women with endometriosis: which phenomena permeate the delays in diagnosis?

This article aims to understand the network of intersubjectively constructed meanings that characterize the phenomenon of endometriosis in the lives of affected women, balancing micro and macrosocial perspectives. This is a qualitative research based on the autobiographical narrative technique of sociologist Fritz Schütze, who explored the experience of 29 women with endometriosis. The analysis was performed according to the reconstructive method proposed by Schütze. Beyond the schematic structure based on indexed data, two theories emerged: structural neglect legitimized by gender issues and barriers and shortcuts in the care network. The narratives reveal the institutionalization of gender issues in health services as a reflection of relationships embedded in the social structure. Neglect, psychiatrization of female suffering, centrality of actions in reproductive function and early medicalization of the female body were social phenomena identified in the narratives. These structural aspects, legitimized by cultural violence, are symbiotically related to lapses in the care network. Coping with this phenomenon demands more than the reorganization of care lines according to the integrality paradigm, although it emerges as a possibility. Understanding the gender-related microstructures that underlie social arrangements and care organization, producing institutional violence and multiple sufferings, is crucial.

> Keywords: endometriosis; late diagnosis; narrative; Sociology; Public Health. 